\title{
A comparison of several ways to assess Pulse Wave Transit Time (PWTT) to find "best-PWTT" for prediction of fluid responsiveness
}

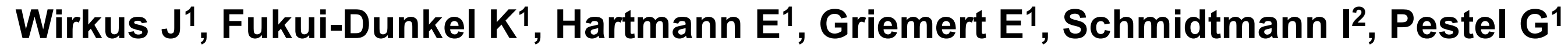 \\ 1) Department of Anaesthesiology, 2) Department of Statistics (IMBEI) \\ Johannes Gutenberg University Medical Center, Mainz, Germany
}

\section{Introduction}

Pulse wave transit time (PWTT) is a flow-based non-invasive monitoring parameter that is assessed in real time at the bedside.

It consists of two parts: pre-ejection period (PEP) and vessel transit time (VTT). The respiratory variation of PEP $(\triangle P E P)$ has been shown to be a predictor of fluid responsiveness (1).

Looking for a noninvasive method to assess blood pressure, PWTT (=PEP + VTT) has been found more suitable than PEP alone (2). Thus, PWTT or the respiratory variation of PWTT ( $\triangle \mathrm{PWTT})$ might be a predictor of fluid responsiveness.

However, at present it is unknown how to obtain PWTT correctly in a clinical setting. Therefore, this study was conducted to find "best-PWTT".

\section{Methods}

Following IRB-approval and written informed consent 40 patients scheduled for major urological were enrolled.

PWTT was monitored continuously (LifeScope $®$ Modell J BSM9101 Nihon Kohden Europe $\mathrm{GmbH}$, Rosbach, Germany). Stroke volume was monitored by Oesophageal Doppler Monitoring (CardioQ-ODM®, Deltex Medical Ltd, Chichester, UK).

In case of hypovolemia a fluid bolus of $7 \mathrm{ml} / \mathrm{kg}$ ideal body weight was administered. An increase in stroke volume of $10 \%$ was considered to reflect fluid responsiveness.

Beginning of PWTT was detected by either R-wave in the ECG, or $\mathrm{Q}$-wave in the ECG. End of PWTT was detected by pulse oximetry either at the finger, or the ear lobe. PWTT measurements were either corrected by Bazett's formula (3), or were left uncorrected.

PWTT was analyzed either as monitored, or the respiratory variation of PWTT ( $\triangle \mathrm{PWTT})$ was analyzed.

ROC curves and corresponding AUCs were used to compare the 16 methods of determing PWTT, a Wilcoxon test was used to discriminate fluid responders from non-responders.

\section{Results}

87 fluid boluses were given. 66 datasets were complete and were used for ROC analysis.

"Best-PWTT" is assessed by the respiratory variation of PWTT $(\triangle \mathrm{PWTT})$, with the heart rate corrected by Bazett's formula.

The beginning of PWTT is detected by the R-wave in ECG, the end is detected by pulse oximetry attached at the earlobe.
AUC is 0.716 , the Wilcoxon test showed a p-value of 0.014 .

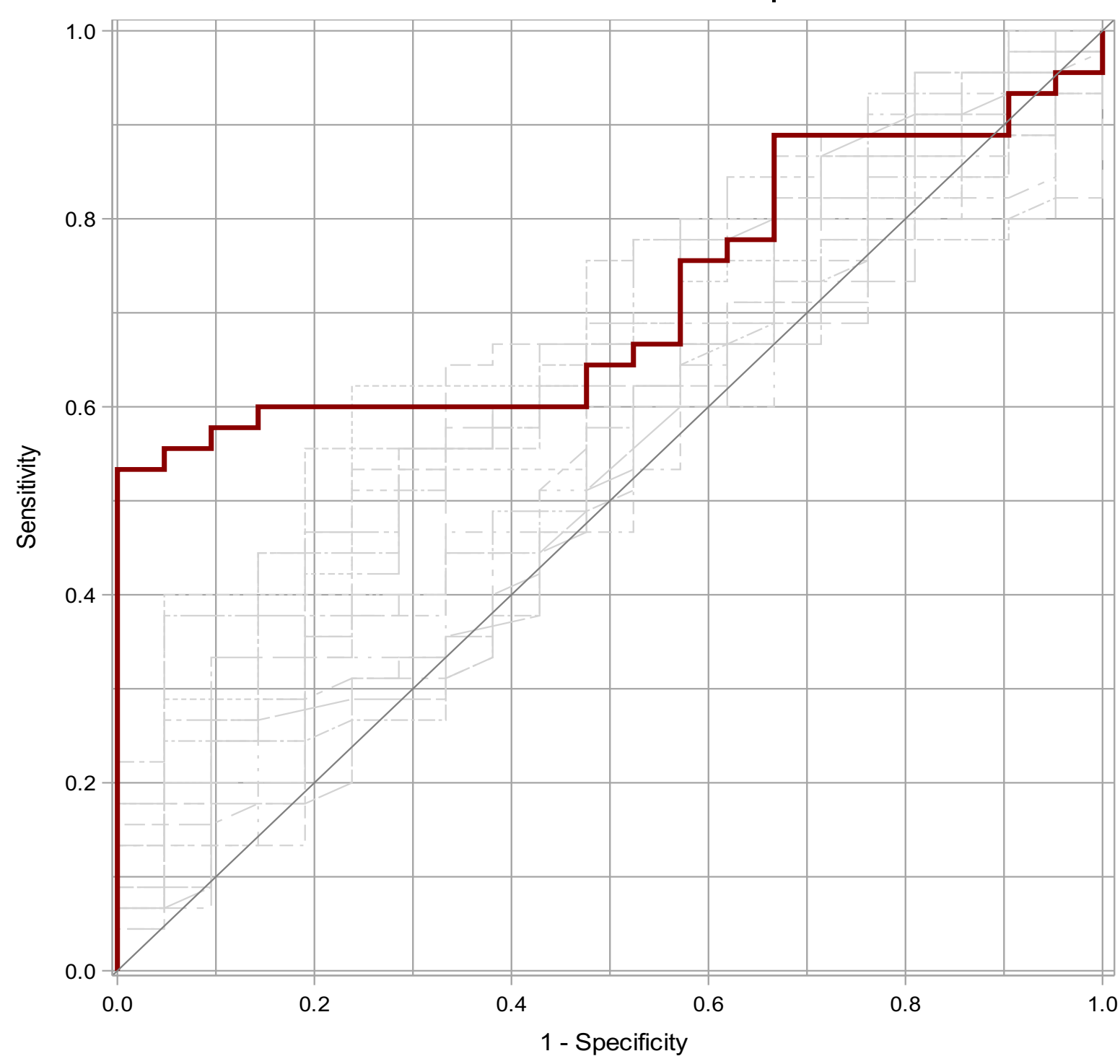

Figure 1: Comparison of the 16 methods to determine PWTT Best-PWTT (AUC 0,7164)

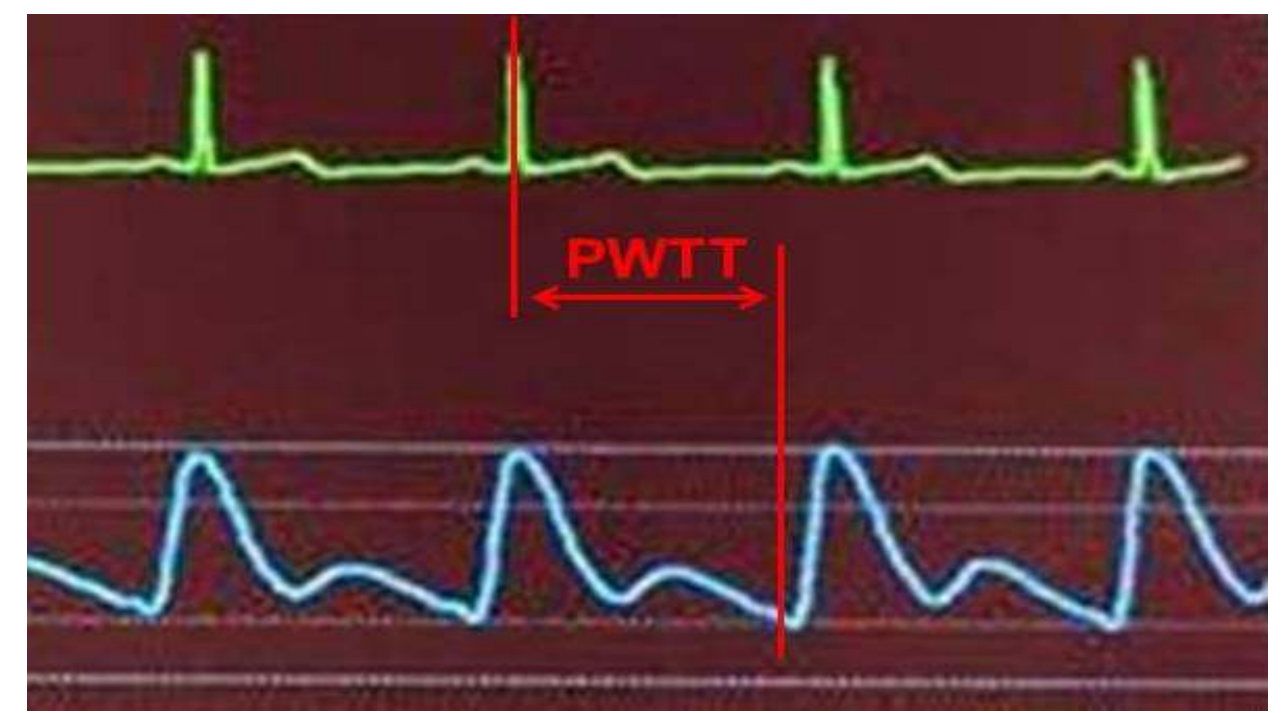

Figure 2: PWTT on monitor

\begin{tabular}{|c|c|c|c|c|c|c|}
\hline $\begin{array}{c}\text { Age } \\
\text { [Years] }\end{array}$ & $\begin{array}{c}\text { Weight } \\
\text { [kg] }\end{array}$ & $\begin{array}{c}\text { Height } \\
\text { [cm] }\end{array}$ & $\begin{array}{c}\text { BMI } \\
{\left[\mathrm{kg} / \mathrm{m}^{2}\right]}\end{array}$ & $\begin{array}{c}\text { Gender } \\
\text { (M:F) }\end{array}$ & $\begin{array}{c}\text { ASA } \\
\text { (I : II : III } \\
: \text { IV) }\end{array}$ & $\begin{array}{l}\text { Fluid- } \\
\text { respond } \\
\text { er }\end{array}$ \\
\hline $\begin{array}{c}59,42 \\
( \pm 9,66)\end{array}$ & $\begin{array}{c}81,8 \\
( \pm \\
16,81) \\
\end{array}$ & $\begin{array}{c}175,3 \\
( \pm \\
11,36) \\
\end{array}$ & $\begin{array}{c}26,53 \\
( \pm 4,7)\end{array}$ & 30: & $\begin{array}{c}0: 24: \\
16: 0\end{array}$ & $\begin{array}{c}28 / 39 \\
(71,8 \%)\end{array}$ \\
\hline
\end{tabular}

Table 1: patient population

\section{Conclusion}

Various ways to assess PWTT are not created equal, "best PWTT" should be used. Further clinical studies are required. 